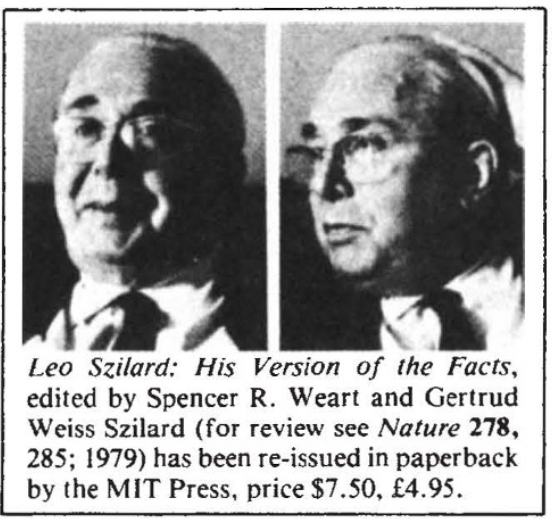

$1: 500,000$ and $1: 75,000$, indicate subsurface temperatures in areas of geothermal interest where the density of subsurface temperature measurements is highest.

Compiling these maps has clearly involved assembling vast amounts of subsurface temperature data (otherwise not readily accessible), and where the density of these observations is high - in the upper kilometre or so of regions of known geothermal potential - the maps may be regarded as reasonably accurate summaries of the available information. Their use is limited, though, when the density of observation is low and when extrapolation over depths of several kilometres is required.

Anyone comtemplating buying this book should look first at Plate 2, which shows the density of the available heat flow information in the EEC, and at Plate 39 which indicates the amount of information provided by boreholes. Next they should read, in any one of six languages, the fourpage introductory text which gives a brief exposition of how the maps were compiled and of the pitfalls involved in making the kind of extrapolation outlined above. (One point not dealt with adequately is the error involved in assigning values of conductivity and heat production when extrapolating temperatures downwards; the compiler's assumption that the likely uncertainty in these parameters is $10-15 \%$ is a wildly optimistic one, and leads him to place misleadingly small error bars on the temperature estimates that he makes.)

Having taken these steps one should be convinced of the difficulties involved in predicting subsurface temperatures from the information available at present, and hence that this book is of little use as a predictor of geothermal resources. The book's remaining attribute, on which it should be judged, lies in the compilation of information that it represents. It is a shame, therefore, that the introduction is so cursory, that so little indication is given of the reliability of the data, and that it was thought necessary to present the information in this elaborate guise.

Philip England is a Research Fellow in the Department of Earth Sciences, Bullard Laboratories, University of Cambridge.

\title{
Herbal facsimiles
}

\section{Sandra Raphael}

Herbarium Apulei Platonici (Vol.I) and Herbolario Volgare (Vol.II). Facsimile reprints. Introductions by Erminio Caprotti and William T. Stearn. Pp.CXXII + 566. (Edizioni Polifilo: Milan, 1979.) Both volumes L.85,000.

A NEW pair of facsimiles reprints the first Latin and the first vernacular herbals published in Italy, the former in 1481, the latter in 1522 . The 1481 book, probably the earliest illustrated herbal printed, is the Herbarium of Pseudo-Apuleius, a GraecoRoman compilation with mediaeval trimmings, surviving in a multitude of manuscripts that indicate its status as a standard source of information on medicinal plants. The crude, diagrammatic woodcuts can have given little help in the identification of the plants described.

The 1522 Herbolario Volgare took both its text and its illustrations from the Latin Herbarius printed by Peter Schoffer, Gutenberg's successor, in 1484. The text is another miscellany from an unknown hand, but its pictures are a decorative improvement on those of the Apuleius. The Iringo (sea-holly) is shown here, a plant whose candied roots were regarded as an aphrodisiac as late as the seventeenth century.

Professor Stearn's introductory essay appears in both Italian and English, and the books are fine examples of the exquisite printing of Mardersteig's Stamperia Valdonega.

Sandra Raphael is a Senior Editor in the Dictionary Department of Oxford University Press. Her book on illustrated herbals, title?, written in collaboration with Wilfrid Blunt, was published late in 1979.

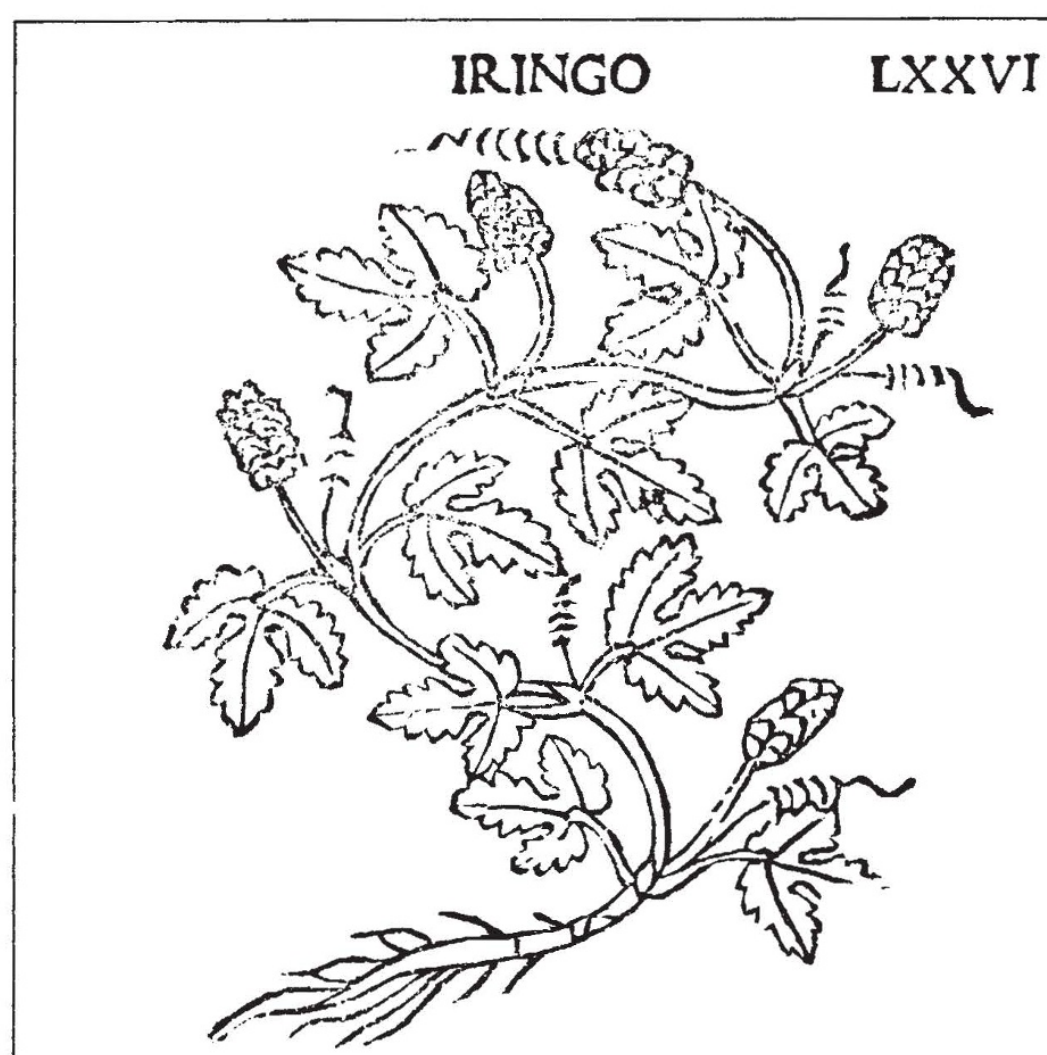

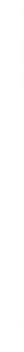

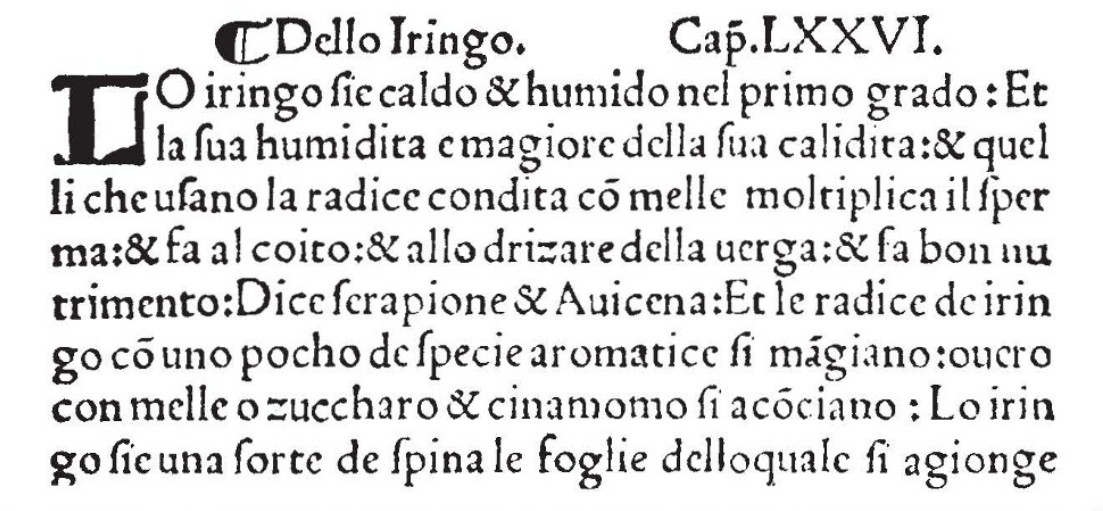

